\title{
Is Foot Asymmetry a Correlate of Hand Performance Asymmetry? Evidence from the Jamaican Symmetry Project
}

\author{
Robert Trivers • Brian G. Palestis • Bernhard Fink • John T. Manning
}

Published online: 21 October 2014

(C) Springer International Publishing 2014

\begin{abstract}
Handedness is likely to be controlled by many genetic variants, some of which are in sex-dependent genes that also influence body asymmetry. One such asymmetry may be in foot length. Levy and Levy (Science, 200, 1291$1292,1978)$ reported that right-handed males have longer right feet than left and left-handed males have longer left feet than right, while this trend was found to be reversed in females. Subsequent studies, however, were unable to replicate this effect. Here, we consider the relationship between foot asymmetry and asymmetry of hand performance in a sample of 251 children from the Jamaican rural countryside. Foot length was measured and asymmetry was calculated (LR). An Annett peg test was used to measure speed of hand performance for right and left hands. Lateralised hand performance (LHP) was calculated by dividing the right-hand time by the left-hand time (i.e. LHP $<1=$ faster right hands). For boys, $\mathrm{L}-\mathrm{R}$ foot length asymmetry was positively correlated to right-hand times and to LHP, and the relationships were independent of age. It is notable that the larger the relative size of the right foot, the faster the speed of the right hand, but so also the smaller the relative size of the right foot, the slower the speed of the right hand - the distribution is continuous and
\end{abstract}

\footnotetext{
R. Trivers

Graduate Program in Ecology and Evolution, Rutgers University, New Brunswick, NJ, USA

B. G. Palestis

Department of Biological Sciences, Wagner College, Staten Island, NY, USA

B. Fink

Institute of Psychology and Courant Research Center Evolution of Social Behavior, University of Göttingen, Göttingen, Germany

J. T. Manning $(\bowtie)$

Department of Psychology, Northumbria University,

Newcastle-upon-Tyne, UK

e-mail: john.manning@northumbria.ac.uk
}

significant. In girls, foot length asymmetry did not correlate with hand speed. Thus, we have replicated the Levy and Levy effect in boys, but not girls. We discuss these results in relationship to the influence of sex-dependent genes and foetal sex steroids on brain and body lateralisation.

Keywords Foot asymmetry $\cdot$ Foot length $\cdot$ Hand performance $\cdot$ Laterality $\cdot$ Sex steroids $\cdot$ Jamaica

\section{Introduction}

Right-handedness is an ancient human trait that is found across all societies (Ludwig 1932; Marchant and McGrew 1998; Raymond and Pontier 2004). It develops early in ontogeny, tends to be sex-dependent with females being more likely right-handed than males (Papadatou-Pastou et al. 2008) and is highly heritable (Annett 1964, 2002; Llaurens and Faurie 2009) with the possible involvement of at least 40 loci (McManus et al. 2013). Recent genome-wide association studies, with handedness measured from a pegboard task, revealed strongest association with a variant located in the PCSK6 gene-an enzyme that cleaves nodal into an active form. Nodal triggers the development of left/right asymmetry in bilaterally symmetrical invertebrates and vertebrates (Grande and Patel 2009; Mercola and Levin 2001; Scerri et al. 2011). This link has led Brandler et al. (2013) to propose that handedness is a polygenic trait, controlled in part by the molecular mechanisms that establish body asymmetry (for a review of possible genetic and environmental influences on handedness see McManus et al. 2013).

Associations between handedness and brain and visceral asymmetries have been documented (for review see Brandler et al. 2013). However, little is known about the relationship between handedness and morphological asymmetry. One, not unexpected, association is between hand size and handedness. 
Right-handed individuals have larger right hands than left hands, but the hands of left-handers are close to being symmetric in size (Purves et al. 1994). This hand asymmetry may arise as the result of differential use of the hands. More surprisingly, there may also be a sex-dependent correlation between handedness and foot length asymmetry. Levy and Levy (1978) examined this in a study of 98 females and 52 males (including children $<6$ years) from the USA. Foot asymmetry was rated on a scale ranging from +3 to -3 (for right-left differences), and handedness was assessed through interviews by asking people on their hand preference in unimodal activity. It was found that right-handed males had longer right feet and left-handed males had longer left feet. In females, these relationships were reversed. The results in children resembled those observed in adults, leading the authors to conclude that pubertal hormones could not have affected the findings. Levy and Levy further concluded that the asymmetric development of foot size is governed by the same genetic mechanisms that determine handedness. Since then, there have been many attempts to replicate these findings, but Levy and Levy's findings on the association between handedness and foot asymmetry could not be confirmed (Mascie-Taylor et al. 1981; Yanowitz et al. 1981; Peters et al. 1981; Orsini and Satz 1985).

Means and Walters (1982) considered both foot and hand size in a sample of 77 male and 79 female children (4-9 years) in the USA and replicated the Levy and Levy effect, but this time, in the hands and not in the feet. These authors asked children their preferred hand for activities such as writing, drawing or cutting. Foot size was measured using a custommade measuring device, resembling those used in shoe stores, and hand size was measured with a ruler from the crease proximal to the palm to the tip of the longest finger. It was found that right-handed boys had longer right hands than left and left-handed boys had longer left hands than right. In addition to the non-significant result from foot length measurement, there was also no association of size and asymmetry detected in children's footprints at birth, possibly because of the use of only two asymmetry categories (right-greater-thanleft and right-not-greater-than-left). Means and Walters concluded that the detected sex-dependent relationship on hand size and handedness is consistent with the finding of Levy and Levy (1978) on foot size, while the failure to replicate this finding with foot size is not. The authors suggest that one reason for this inconsistency may be found in the different levels of maturation between the children in their study (4 9 years) and those in the Levy and Levy study ( $<6$ years) and related sample sizes. Moreover, it was concluded that the sexand handedness-related asymmetry in foot size may be either small or developed later in ontogeny.

This present paper reports an attempt to replicate the findings of Levy and Levy (1978) on relationships of sex-related foot size asymmetry and handedness in a sample of children from a long-term study (the Jamaican Symmetry Project (JSP)) from a rural Jamaican population (Trivers et al. 1999). The JSP consists of a cohort of children that were first measured in 1996 when participants were 5-11 years. Previous studies that have failed to replicate the Levy and Levy results considered handedness as a discrete discontinuous variable. Thus, non-right-handed participants were typically present in small numbers. We assessed relative hand performance using an Annett peg-moving task (Annett 2002), thus considering it as a continuous measure of hand preference.

\section{Method}

The Jamaican study population is described in detail in Trivers et al. (1999). It comprises 288 children (155 boys, 131 girls and 2 of unknown gender) drawn from Southfield in the parish of St. Elizabeth. The children were recruited from three schools in the area (Top Hill Primary, Mayfield All/Age and Epping Forest All/Age), and the sample had an age range of $5-11$ years (mean age $=8.18 \pm 1.73$ ).

Foot length was measured twice to the nearest millimetre using a tape measure. The measurement landmarks were the anterior tip of the first toe to the posterior tip of the heel, and all measurements were taken by the same experienced measurer.

We assessed relative hand performance by the Annett peg-moving task (Annett 1970, 2002). Trials were carried out in January 1996. A pegboard with two rows of ten holes was used. Participants moved, with one hand, ten pegs from a row or holes to an empty row of holes situated about 5 in. in front. Each trial was timed from the moment the hand touched the first peg until the last peg was placed in its hole. There were ten trials in all, five for each hand. Mean left- and right-hand times were then calculated. Lateralised hand performance (LHP) was calculated by dividing the mean right-hand time by the mean left-hand time, i.e. the greater the LHP, the greater the tendency to perform faster with the left hand relative to the right hand. The subjects who had a faster time with the right hand compared to the left hand had an LHP $<1$.

\section{Results}

Foot Asymmetry

The asymmetry of foot length was calculated by subtracting right foot length from left foot length (foot asymmetry=L-R). With regard to the first and second measurements of foot length, we calculated repeatabilities $\left(r_{1}\right)$ in the form of intra- 
class correlation coefficients using model II single factor ANOVA tests (Zar 1999) and used repeated measures ANOVA tests to calculate the ratio $(F)$ between group mean squares (i.e. the real differences between individuals) and the error mean squares (i.e. the error in our repeated measures). The repeatability of the signed foot asymmetries was significant with $r_{1}=0.67, F=5.07, p<0.0001$. This showed that the difference in foot asymmetry between participants was significantly greater than the measurement error for individual asymmetry. Therefore, we calculated an average signed foot asymmetry per individual and used this in all subsequent analyses.

The mean unsigned foot asymmetry deviated slightly from zero (i.e. there was a weak tendency for left feet to be longer than right), but this trend towards directional asymmetry was not significant $(n=272$, one-sample $t$ test with mean set at zero: mean asymmetry $=0.06 \mathrm{~mm}, t=0.96, p=0.34)$. There was non-significant skew $(v=-0.26, p=0.08)$ in the signed asymmetries and highly significant leptokurtosis $(v=5.04$, $p<0.0001$; Trivers et al. 1999). There were no significant differences between boys and girls in their mean asymmetry (boys, $n=148$ : mean asymmetry $=0.08 \pm 0.98 \mathrm{~mm}$; girls, $n=$ 123: mean asymmetry $=0.04 \pm 1.02 \mathrm{~mm} ; t=0.33 ; p=0.74$ ).

\section{Hand Performance Asymmetry}

Right- and left-hand speeds were both recorded for 251 children (135 boys, 116 girls). There were no significant sex


$1.95 \mathrm{~s}$; girls, $12.06 \pm 1.84 \mathrm{~s} ; t=0.57 ; p=0.57)$ or left-hand speed (boys, $13.78 \pm 2.22 \mathrm{~s}$; girls, $14.05 \pm 2.29 \mathrm{~s} ; t=0.97 ; p=$ $0.33)$. However, boys had significantly faster left hand relative to right-hand speed than did girls (boys: $\mathrm{LHP}=0.89 \pm 0.70$, girls: $\mathrm{LHP}=0.86 \pm 0.80, t=2.67, p<0.01)$.

\section{Correlations Between Foot Asymmetry and Hand}

Performance Asymmetry

We were expecting sex differences in the direction of slope in the relationships between signed foot asymmetry and LHP (i.e. a positive slope for boys and a negative slope for girls). Therefore, we considered boys and girls separately. For boys, as expected, foot asymmetry was positively related to hand speed and LHP, and the relationship was significant for foot asymmetry and right hand $(r=0.23, p<0.01$, Fig. 1$)$ but not left hand $(r=0.12, p=0.16)$, and significant for LHP $(r=0.21$, $p<0.05$, Fig. 2). These correlations remained significant after the removal of the effect of age (multiple regression, standardised coefficients, right hand, $b=0.13 ; p<0.05$ and LHP, $b=0.18 ; p<0.05$ ). For girls, there were no relationships between foot asymmetry and hand performance (right hand, $r=0.01 ; p=0.89$ and left hand, $r=0.02 ; p=0.85$ and LHP, $r=$ $-0.003 ; p=0.98)$.

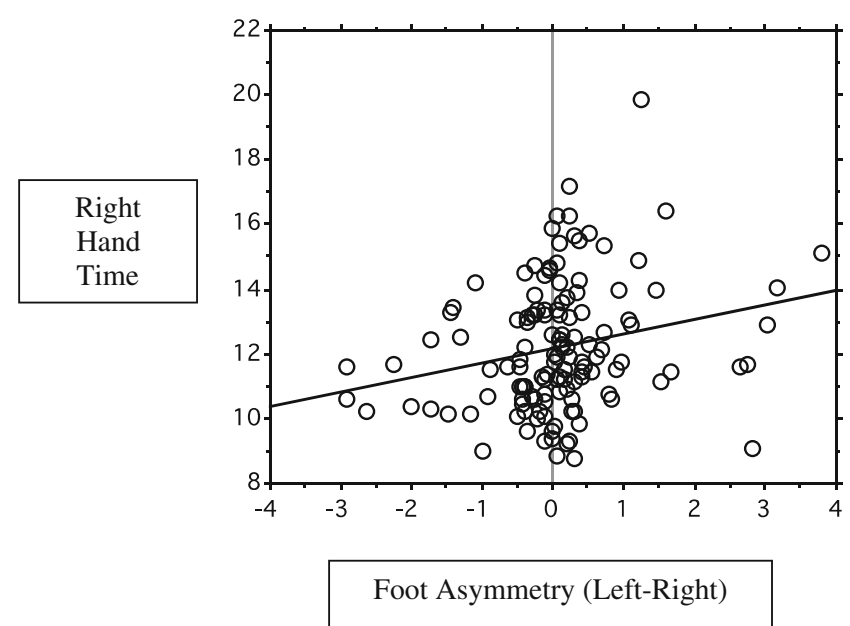

Fig. 1 The relationship in boys between the mean time for the right hand in the peg test and the asymmetry of foot length $(\mathrm{L}-\mathrm{R})$

\section{Discussion}

This study aimed to replicate findings of Levy and Levy (1978) on relationships of sex-related foot size asymmetry and handedness in a sample of children from a rural Jamaican population. We found that boys with longer right feet than left tended to have fast right hands in a peg-moving task, and their right-hand speed tended to be faster than their left-hand speed (i.e. LHP $<1$ ). This pattern was reversed in boys whose left foot length was greater than their right. There were no significant effects in girls. Thus, the present results replicate those of Levy and Levy (1978) in a sample of boys and men, but do not support their findings for girls and women.

Our study had fewer limitations than previous reports. Our two variables (handedness and foot asymmetry) were measured on a continuous scale rather than the less precise discontinuous scale for handedness (Levy and Levy 1978;

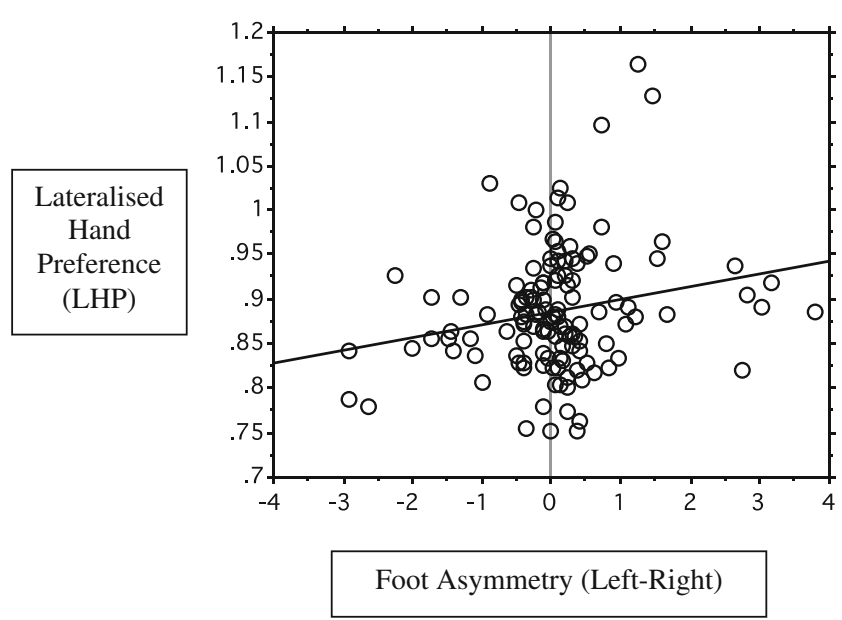

Fig. 2 The relationship in boys between lateralised hand preference (LHP: mean time for the right hand/mean time for the left hand) and the asymmetry of foot length (L-R) 
Mascie-Taylor et al. 1981; Peters et al. 1981; Yanowitz et al. 1981; Means and Walters 1982; Orsini and Satz 1985) or foot length (Levy and Levy 1978; Orsini and Satz 1985). There may be geographical and ethnic variation in handedness (Leask and Beaton 2007; Raymond and Pontier 2004). Our sample was ethnically homogenous (all Afro-Caribbean children), whereas it is unclear whether the earlier samples consisted of one or a mix of ethnicities. However, it remains to be demonstrated whether the present findings can be extended to adults and to other ethnicities.

The sex difference in the links between foot asymmetry and hand performance asymmetry suggests an influence of early sex steroids and more specifically prenatal hormones. With regard to hand performance, Manning et al. (2000) investigated the relationship between LHP and digit ratio (2D:4D) - a biomarker for prenatal testosterone - in rural Jamaican children (the JSP; Trivers et al. 1999). It was found that right hand 2D:4D correlated negatively with leftward performance asymmetry in the Annett pegboard task, and this was especially true for boys. This relationship between low right 2D:4D (or low right 2D:4D relative to left 2D:4D) and left-handedness was found in adults by Nicholls et al. (2008), Manning and Peters (2009) and Beaton et al. (2011). Also, Fink et al. (2004) reported that in a sample of 38 boys and 41 girls aged 611 years $2 \mathrm{D}: 4 \mathrm{D}$ correlated negatively with left-hand performance. All these studies concluded that prenatal testosterone affects brain lateralization such that high levels of prenatal testosterone results in faster left-hand performance relative to right. Our present data expand those reported by Manning et al. (2000) by linking foot asymmetry to hand performance, thus suggesting that the relationship between these two measures could be moderated by prenatal testosterone. Levy and Levy already suggested that foetal sex steroids may play an important role in determining both the relative maturational rates of the right and left sides of the brain and feet. As expected and consistent with this model, a sex difference in LHP was found in this present study such that boys tended to show higher LHP than girls. However, the lack of a significant sex difference in the directional asymmetry of foot length was unexpected and requires further investigation.

The findings of Levy and Levy linking foot asymmetry and handedness have been perceived as puzzling and inexplicable in the scientific literature. This is especially so in the light of the non-replication of their findings. However, we feel that the recent links between genes that influence both L-R body asymmetries and handedness have placed the Levy and Levy report in a different light. In this context, our findings lend some support to the hypothesis of Brandler et al. (2013) that handedness is under the control of genes that also contribute to the development of left/right body asymmetry.
Acknowledgments Preparation of the manuscript was supported by the Biosocial Research Foundation and the German Research Foundation (DFG FI 1450/7-1). The Enhanced Education Foundation provided funding for RT.

\section{References}

Annett, M. (1964). A model of the inheritance of handedness and cerebral dominance. Nature, 204, 59-60.

Annett, M. (1970). A classification of hand preference by association analysis. British Journal of Psychology, 61, 303-321.

Annett, M. (2002). Handedness and brain asymmetry: the right shift theory. Hove: Psychology Press.

Beaton, A. A., Rudling, N., Kissling, C., Taurines, R., \& Thome, J. (2011). Digit ratio (2D:4D), salivary testosterone, and handedness. Laterality, 16, 136-155.

Brandler, W. M., Morris, A. P., Evans, D. M., Scerri, T. S., Kemp, J. P., et al. (2013). Common variants in left/right asymmetry genes and pathways are associated with relative hand skill. PLoS Genetics, 9, e1003751.

Fink, B., Manning, J. T., Neave, N., \& Tan, U. (2004). Second to fourth digit ratio and hand skill in Austrian children. Biological Psychology, 67, 375-384.

Grande, C., \& Patel, N. H. (2009). Nodal signalling is involved in leftright asymmetry in snails. Nature, 457, 1007-1011.

Leask, S. J., \& Beaton, A. A. (2007). Handedness in Great Britain. Laterality, 12, 559-572.

Levy, J., \& Levy, J. M. (1978). Human lateralization from head to foot: sex-related factors. Science, 200, 1291-1292.

Llaurens, R., \& Faurie, C. (2009). Why are some people left-handed? An evolutionary perspective. Philosophical Transactions of the Royal Society B, 364, 881-894.

Ludwig, W. (1932). Das Rechts-links problem im Tierreich und beim Menschen. Berlin: Springer.

Manning, J. T., \& Peters, M. (2009). Digit ratio (2D:4D) and hand preference for writing in the BBC Internet Study. Laterality, 14, 528-540.

Manning, J. T., Trivers, R. L., Singh, D., \& Thornhill, R. (2000). The 2nd: 4th digit ratio and asymmetry of hand performance in Jamaican children. Laterality, 5, 121-132.

Marchant, L. F., \& McGrew, W. C. (1998). Human handedness: an ethological perspective. Human Evolution, 13, 221-228.

Mascie-Taylor, C. G. N., McLarnon, A. M., \& Lanigan, P. M. (1981). Foot length asymmetry, sex and handedness. Science, 212, 14161417.

McManus, I. C., Davison, A., \& Armour, J. A. (2013). Multilocus genetic models of handedness closely resemble single-locus models in explaining family data and are compatible with genome-wide association studies. Annals of the New York Academy of Sciences, 1288 , 48-58.

Means, L. W., \& Walters, R. E. (1982). Sex, handedness and asymmetry of hand and foot length. Neuropsychologia, 20, $715-719$.

Mercola, M., \& Levin, M. (2001). Left-right asymmetry determination in vertebrates. Annual Review of Cell and Developmental Biology, 17, 779-805.

Nicholls, M. E., Orr, C. A., Yates, M. J., \& Loftus, A. M. (2008). A new means of measuring index/ring finger (2D:4D) ratio and its association with gender and hand preferences. Laterality, 13, 71-91.

Orsini, D. L., \& Satz, P. (1985). Pedal asymmetries and handedness. Journal of Clinical and Experimental Neuropsychology, 7, 127129. 
Papadatou-Pastou, M., Martin, M., Munafo, M. R., \& Jones, G. V. (2008). Sex differences in left-handedness: a meta-analysis of 144 studies. Psychological Bulletin, 134, 677-699.

Peters, M., Petrie, B., \& Oddie, D. (1981). Foot length asymmetry, sex and handedness. Science, 212, 1417-1418.

Purves, D., White, L. E., \& Andrews, T. J. (1994). Manual asymmetry and handedness. Proceedings of the National Academy of Sciences of the United States of America, 91, 5030-5032.

Raymond, M., \& Pontier, D. (2004). Is there geographical variation in human handedness? Laterality, 9, 35-51.
Scerri, T. S., Brandler, W. M., Paracchini, S., Morris, A. P., Ring, S. M., et al. (2011). PCSK6 is associated with handedness in individuals with dyslexia. Human Molecular Genetics, 20, 608-614.

Trivers, R. L., Manning, J. T., Thornhill, R., \& Singh, D. (1999). Jamaican Symmetry Project: long-term study of fluctuating asymmetry in rural Jamaican children. Human Biology, 71, 419-432.

Yanowitz, J. S., Satz, P., \& Heilman, K. M. (1981). Foot length asymmetry, sex and handedness. Science, 212, 1418.

Zar, J. H. (1999). Biostatistical analysis. Upper Saddle River: Prentice Hall. 